\title{
Study on Formation of Methods for Safety Accounting
}

\author{
Enzhu Li \\ School of Management, China University of Mining \& Technology, Xuzhou 221116, China \\ School of Accounting, Shandong University of Finance, Ji'nan 250014, China \\ E-mail: lez11513@163.com \\ Xueyi Zhu \\ School of Management, China University of Mining \& Technology, Xuzhou 221116, China \\ E-mail:xyz@xyz588.com \\ Yishu Wang \\ School of Accounting, Shandong University of Finance, Ji'nan 250014, China \\ E-mail:wys124@163.com
}

Supported by the Philosophy \& Social Science Foundation of Department of Education of Jiangsu Province, China (No.06SJD790053)

\begin{abstract}
By theoretical analysis, this paper firstly discusses the effects of safety accounting's basic methods systematically, studying the effects of macro economic factors on safety, the effects of production accidents on social economy, the law of safety activities' effects, and the mode of safety investment resources' finance management and finance report. Based on accounting, management, and statistics that are founded on methods of safety accounting, this paper constitutes and describes a brand-new system for safety accounting's basic methods in detail, insisting that methods of safety accounting are composed of checking and information disclosing method, management method, value-measuring method, and effect-assessing method.
\end{abstract}

Keywords: Accounting, Safety, Method, Formation

\section{Introduction}

Considering the concept of sustainable development, the development means not only growth of economy, but also concerning resources, environment, social progresses, and human comprehensive development. Safety production is an important part of sustainable development, being a sign of social civilization and progress. Safety production demands for all branches' participation and researches. The participation of accounting in safety management is a must objectively. Accounting possesses special advantages over other specialties for the safety of resource management. It is necessary to set up an independent theoretical system for safety accounting, which helps the newly-built safety accounting research not only the micro safety resource planning but also the macro safety resource allocation. This paper will present some personal opinions on the base and the specific methods of safety accounting that generates from the participation of accounting in safety production management.

\section{Effects of safety accounting's basic methods}

Safety accounting is a kind of management activity used by organizations where production accidents may happen. By safety accounting, organizations use multiple measurement units, mainly currency, to reflect and control the safety investment resources, the process and result of evaluating and repaying accident losses. The purpose is to provide with exact, timely, and effective information about safety resource investment, use, production accidents, losses, and repayments for users of safety accounting information who can make relevant decision, in order to the improve the whole social production's economic benefits and social benefits comprehensively. Therefore, the system of safety accounting's basic methods chiefly includes following aspects.

\subsection{To research the effects of macro economic factors on safety}

Discuss the effects of macro economic factors, such as social economic system, economic structure, economic development, on safety, and the relationship between these factors and human safety activities. Establish the position and the effects of safety goals in social production and social economic development. Discuss the proportion relationship between the growth ratio of safety investment and the development rate of social economy theoretically.

\subsection{To research the effects of production accidents on social economy}

Discuss the law of accidents' losses and its influences on social economy at different times (time), in different 
regions (industries, branches, and other spaces), at different scientific and technological levels, under different productivities. Explore theories and methods for analyzing, evaluating accidents and losses, especially the scientific, exact measurement theories and methods according to losses' indirect, implicit, and chain characteristics, which can serve as bases for mastering the effects of production accidents on social economy.

\subsection{To research the law of safety activities' effects}

There are both connections and differences between safety benefits and production benefits. Safety benefits include not only economic benefits, but also non-value factors (healthy, stability, happiness, etc.) and other social benefits. Under this condition, it is hard to assess safety benefits. Therefore, to research safety benefits' complexity and its lasting effects, and to disclose the comprehensive benefits of safety provide with scientific causes for assessing and controlling safety economic activities.

\subsection{To research the mode of safety investment resources' finance management and finance report}

Discuss the feasibilities' demonstration methods for safety investment's economic resource projects, and the investment policies. Explore the mode of safety investment resources' finance reports that is based on modern accounting theories, and relevant safety resource management methods, such as audition system, and statistic of accidents' losses and repayments. Realize the reasonable use of national safety investment resources and the optimal effects of investments, including people, capitals, and materials.

\section{Formation base of methods for safety accounting}

\subsection{The accounting base}

Because safety accounting is a component and a new branch of accounting system, the methods system of accounting is the natural base of methods system for safety accounting. The basic effects chiefly include following aspects. The first is the wide implement of mature accounting methods, such as setting up accounts, and multiple accounts. The second is the adoption of accounting methods, such as calculation methods of costs, calculation methods of depreciation, allocation of expenses, and accounting methods of taxes. The third is the reform of some accounting methods, such as accounting reports that should be reformed based on finance reports' basic types and structures considering the contents reflected by safety accounting, adding new necessary items according to users of safety accounting information, which can help to exert the effects of safety accounting better. Besides, some special accounting also has certain influences on the formation of methods for safety accounting, such as human resource accounting, and social responsibility accounting. These influences mainly focus on relevant accounting methods' introduction and references, and the contents' reformation and innovation.

\subsection{The management base}

The so-called management is to design and retain a nice environment in which people can accomplish supposed goals with high efficiency (Harold Koontz \& Heinz Weihrich, 1993). Management is inevitable for all social production process. Management, being the lead in all fields, occupies a dominant position. It is the soul of an organization. And it can guarantee the accomplishment of organizational goal.

Management, as a kind of social activity, centers in people. People are not only the subjects of management (managers) but also the objects (followers). Everyone is at certain management level. On one hand, he or she governs his or her followers or materials. On the other hand, he or she is governed by his or her governor. By this way, a people-oriented management chain is in form. In management, the root is to motivate people's enthusiasm and dig out their creativity. That is the principle of people in management. The people-oriented safety management is to activate workers' enthusiasm in the whole production process. All people join in and guarantee the safety and production. On one hand, it emphasizes that the fundamental target of safety production is to protect workers' healthy and safety. On the other hand, it has to depend on people's enthusiasm and creativity to achieve safety production. The safety management is a process of organizing and employing sorts of material sources, such as human resources, materials, and capitals, in order to achieve safety production. It adopts the management mechanism, namely plan, organize, direct, coordinate, and control, to control the natural, mechanic, or material unsafe factors and human unsafe activities, avoiding casualties and hurts, ensuring workers' safety and healthy, and guaranteeing the production.

\subsection{The statistics base}

From the development and history of accounting and statistics, statistical methods and accounting methods overlapped in nature. And this is a must in a sense. A. C. Littleton, a famous American accounting expert, thought that accounting connects with statistics in the mathematical aspect. Therefore, in essence, accounting methods and statistical methods come down in one continuous line. Although accounting has the characteristics of economics and its methods have the features of statistics, their processes include classification, collection, and re-classification. 
Therefore, many accounting theories and the practical implements relate with the development of statistics and the introduction of statistical theories. Their relationship between accounting and statistics is mainly reflected by the wide application of statistical methods, as the quantity calculation and analysis methods, in accounting field. Firstly, in the finance accounting aspect, the static factor asset, debt, and ownership in accounting assess are the time indexes in statistics. And the dynamic factor income, expense, and profit are the period indexes in statistics. The principle of weighted mean method and moving weighted mean method for stock pricing is the statistical mean. And the repayment ability, operation ability, and profitability in finance report analysis are the application of principle of statistical relative number in accounting. Secondly, in the management accounting, the application of statistical methods is obvious in its method system for prediction, decision, and control, such as the correlation analysis and regression analysis used by mixed cost decomposition, the trend model used by sales and costs prediction, the probability decision in short-term business decision, the calculation of risk values' standard deviation coefficient in long-term business decision, the regional evaluation in uncertainty decision, the probability budget in general budget, and the factor analysis in standard cost differentiation analysis. All these methods take references from statistical methods and technologies to different degrees. Besides, in finance management, the finance and investment's risk prediction and the capital structure's evaluation also take references from statistical methods and technologies. Therefore, some domestic accounting scholars think that because of the emphases on application of statistical theories and technologies in specific accounting issues, the researches and analyses of accounting issues under uncertainty conditions possess supportive tools (Guangyun Wang \& Yingqi He, 1997). The connection between accounting methods and statistical methods can affect the specific methods of safety accounting, because the safety accounting aims at providing with necessary information for different users in order to improve the economic benefits and the social benefits, what is similar to the general finance accounting and management accounting. Obviously, methods for safety accounting have close connection with statistical methods in many ways. Therefore, statistics should be one of bases for safety accounting methods.

\section{Formation of methods for safety accounting}

Safety accounting methods are necessary fundamental ways in order to reflect and control the objects of safety accounting, and accomplish tasks of safety accounting. Regarding safety accounting as an object of management activity, or regarding it as a specific operation in information system, its contents focus on the processes and results of investing and using the safety resources that relate with safety production. Considering the specific aims of safety accounting, it emphasizes on providing with exact, timely, and effective comprehensive information concerning safety resources' investments and uses, and production accidents' losses and repayments for safety accounting information' users in order to meet the need for decision-making. By accounting management activities, the economic benefits and social benefits of investing and using safety resources can be improved. The complexity of safety accounting and the uniqueness of its aims determine that the basic methods for safety accounting should form a relatively complete system. This system can include four parts as follow.

\subsection{Methods for safety accounting assessing and information disclosing}

The method for safety accounting assessing is fundamental for safety accounting. It assesses the stocks and variables of different safety resources. Theoretically, it includes value assessing and material assessing. But in practice, it chiefly adopts value assessing. Because in essence, safety accounting is a new assessing branch of finance accounting, its methods will inevitably adopt methods of finance accounting, such as the design of accounting items, the set-up of accounting check, the assessment of costs and expenses, and the composition of accounting reports. Similar to common accounting assessing, safety accounting information is mainly disclosed in form of accounting reports internally and externally. And the carriers are various, including words, tables, numbers, graphics, or combination of different forms. The report form is determined by the target users as a matter of fact.

\subsection{Methods for safety accounting management}

Methods for safety accounting management are important components of safety accounting methods. It concerns issues of adopting certain ways to control the safety resources' economic circulation process and result. In form, it includes many specific activities, such as predicting, decision-making, planning, assessing, checking, testing, and analyzing the economic activities related with safety resources.

\subsection{Methods for safety accounting measurement}

Value measurement method is the base for safety accounting assessing and management methods. Because the objects of safety accounting assessing are more complicate, especially the accidents' losses and relevant repayments, as the subjects of assessing, have greater uncertainty, and change frequently, the exactness is restricted by social economic environment, customs, faith, education, and values. Therefore, the measurement is merely relative exact. In order to achieve a comprehensive reflection and control from an accounting viewpoint, the value measurement 
becomes one of fundamental factors that restrict the effectiveness of safety accounting information. Because of the greater uncertainty concerning losses and repayments after accidents, the constitution of safety accounting's value measurement system and the researches on measurement methods should be the core of safety accounting research.

4.4 Methods for checking safety accounting's benefits

Methods for checking safety accounting's benefits aim at examining the safety resources' investment, the safety accidents' losses and repayments, and the result of prediction. Considering the safety resources' investment and the safety accidents' losses and repayments, these methods should include two parts, namely the methods for checking the economic benefits, and the methods for checking the social benefits. The main way is to design an effective checking indexes' system, define the checking indexes' basic constitutional factors, determine the data's effective sources, and the time periods for each check.

\section{Conclusion}

The market economy system determines that all social activities should follow the law of values and the principle of benefits. Similarly, all human safety activities should be in accord with this law and principle. Besides, because the resources (capitals, human resources, and materials) invested in safety production by country, society, and enterprises are limited, the use of resources should be effective, considering both economic thoughts and demonstrations, and specific accounting assessing. In order to make best use of country's limited safety resources and manage them well, it is necessary to explore the researches on safety accounting, developing a series of theories to direct practices. By perfecting the constitution of safety accounting' methods system, we can provide with exact, timely, and effective comprehensive information about safety accidents defending resources' allocation and checking for users to satisfy the need for safety decision on one hand. On the other hand, by applying advanced accounting methods and executing accounting management activities, we can drive the effective utility of safety resources, avoiding economic losses from safety accidents, improving economic benefits and social benefits directly, and contributing to the sustainable development of human society.

\section{References}

Harold Koontz \& Heinz Weihrich. (1993). Management (10th). New York: McGraw-Hill Inc.

Wang, Guangyun \& He, Yingqi. (1997). New development of modern management accountant research method. Accounting Research. No.1. 